๑ Entomologica Fennica. 19 April 2002

\title{
The internal genitalia as a taxonomic tool: description of the relict endemic moth, Coranarta restricta sp. $n$., from the Iberian Peninsula (Lepidoptera: Noctuidae: Hadeninae)
}

José L. Yela

Yela, J. 2002: The internal genitalia as a taxonomic tool: description of the relict endemic moth, Coranarta restricta sp. n., from the Iberian Peninsula (Lepidoptera: Noctuidae: Hadeninae). — Entomol. Fennica 13: 1-12.

A comparative study of the internal genitalia and examination of ecological preferences show that the Iberian populations formerly referred to as Coranarta cordigera (Thunberg, 1788) should be recognised as a distinct species, Coranarta restricta sp. n. Because of its rarity, extremely local distribution, and endemic and relict character, it should be regarded as an endangered species and its potential as a flagship species in conservation programmes is addressed. The phylogenetic and zoogeographical relationships among the species of Coranarta are outlined. The utility of structural matching of internal genitalia in conspecific males and females as a taxonomic tool is discussed, together with the main hypotheses of the evolutionary significance of internal genital differentiation in allopatric species.

J. L. Yela, Area de Zoología, Facultad de Ciencias del Medio Ambiente, Universidad de Castilla-La Mancha, Campus Fábrica de Armas, Avda. Carlos III s.n.,E-45005Toledo,Spain; E-mail:jlyela@amb-to.uclm.es

Received 5 November 2001, accepted 12 December 2001

\section{Introduction}

Berio (1985) and Beck (1991) noted differences between the type species of the hadenine noctuid genus Anarta Ochsenheimer, 1816 (Noctua myrtilli Linnaeus, 1761) and species of the cordigera species group, both in the adult and larval stages (see also Beck 1999). Consequently, Beck (1991) erected Coranarta (type species: Noctua cordigera Thunberg, 1788) for this latter group.

An earlier taxonomic review of this boreo-alpine group by Lafontaine et al. (1987) split Coranarta cordigera, until then considered to have a holarctic distribution, into four species: $C$. cordigera in Europe (from the Ural Mountains westwards), C. carbonaria (Christoph, 1893) in
Siberia and the Far East, C. luteola (Grote \& Robinson, 1865) in North America and C. macrostigma (Lafontaine \& Mikkola, 1987) in western North America. The main criteria for separating these species were differences in the internal genitalia (vesica in males and bursa copulatrix in females). Despite some intraspecific, apparently population-dependent, variability (Yela, in prep.), it has been shown that the three-dimensional structure of the everted and expanded vesica of a given noctuid species generally matches the three-dimensional structure of the expanded cervix bursae or posterior part of the bursa copulatrix of conspecific females (e.g. Hardwick 1958, 1970, Lafontaine 1981, 1987, Lafontaine \& Mikkola 1987, Lafontaine \& Poole 1991, Matthews 1991, 


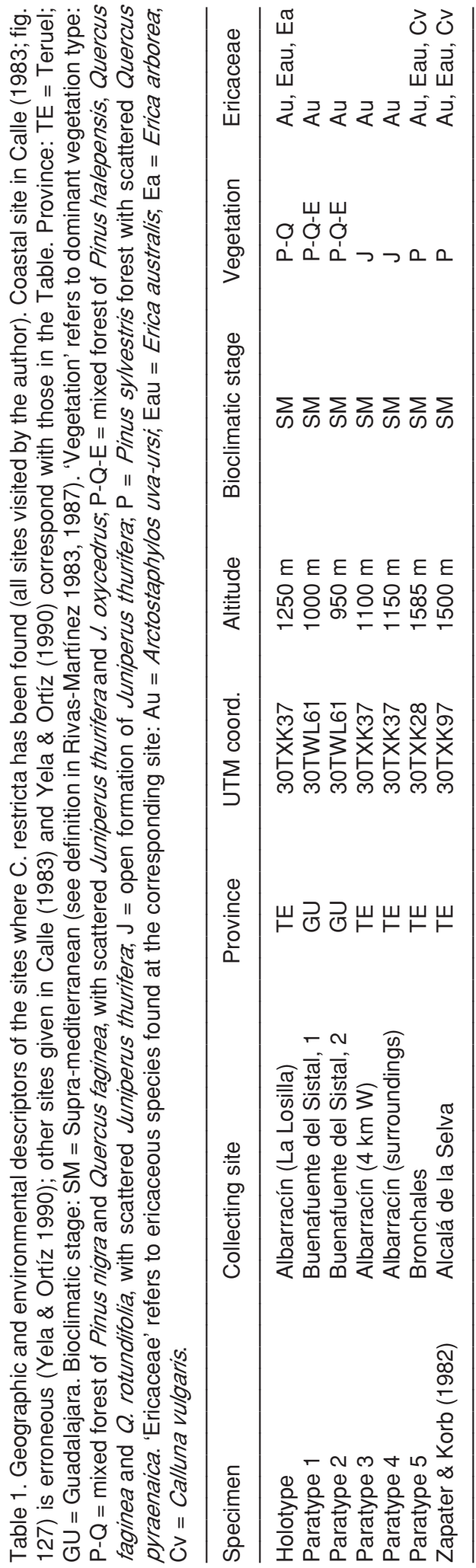

Mikkola 1992, Yela 1992, Lafontaine 1998). There is a causal, functional explanation for this fact, because the success of sperm transfer from the spermatophore(s) to the ductus seminalis depends on the ability of the male to place the spermatophore tip just in front of the opening of ductus seminalis. This has the evolutionary consequence of structural matching of the internal genitalia of both sexes (Callahan \& Chapin 1960, Byers \& Hincks 1978, Lafontaine 1981, Mikkola 1993), brought about by strong stabilizing selection and intersexual coevolution (Mikkola 1993) (cohesion sensu Templeton 1989). Slight differences in the orientation of either structure may make sperm transfer difficult or impossible, even in closely related species (Byers \& Hincks 1978, Lafontaine 1981, Byers \& Lafontaine 1982, Mikkola 1993). The four currently recognised species of Coranarta show differences of this nature, which are thought to be indicative of reproductive isolation (Lafontaine et al. 1987).

During the course of my studies on Iberobalearic Noctuidae, I found evidence that individuals from Spain referred to as $C$. cordigera show remarkable differences in both male $(n=1)$ and female internal genitalia $(n=5)$ from the remaining European populations (see also Yela \& Ortíz 1990, Yela 1998). In addition, the Iberian populations are not restricted to true bogs and peatlands, as is usual in the other species (Mikkola \& Spitzer 1983, Lafontaine et al. 1987), but are instead associated with sites that are seasonally dry and hot in summer and very cold in winter. This led to the question addressed in this paper: are the internal genital differences found in the Iberian populations of a similar degree to those between other congeneric species of Coranarta? If so, the Iberian populations would have to be treated, and described, as a new species.

\section{Material and methods}

\subsection{Field work}

Moths of all species of Coranarta fly in sunshine, so the adults of Iberian Coranarta were collected using a butterfly net. No explicit collecting programme was employed by any of the collectors. I visited all collecting sites to identify their ecological and physiographic characteristics (Table 1) and plant species composition, as well as to search for larvae and their putative host plants. 


\subsection{Genitalia manipulation}

Abdomina were dissected and genitalia mounted using standard techniques. Vesicas and bursas were carefully everted and/or expanded with isopropanol prior to the final mounting in Euparal (e.g. Hardwick 1950, Lafontaine 1981, Lafontaine \& Mikkola 1987, Yela 1992, Fibiger \& Goater in Fibiger 1997). Although Siloprene (Magro 1994) is probably a better mountant, allowing not only full expansion of internal structures and their measurement, but also threedimensional comparisons from all angles, it was not used here because of the irreversibility of the process. Measurements were made using a micrometer incorporated into a standard binocular microscope. Drawings were made using a Bianchi projector, prior to the final mounting (to avoid possible distortion by the cover glass). Spermatophore counts were made using a microscope with $100 \times$ magnification to minimize errors.

\subsection{Statistics}

Basic statistics were calculated using STATISTICA 5.5 (StatSoft 1999).

\subsection{Terminology}

Abbreviations: $\mathrm{MNCN}=$ Museo Nacional de Ciencias Naturales, Madrid (Spain); JLY = José Luis Yela.

\section{Results}

Preliminary doubts about the taxonomic identity of Iberian Coranarta arose from its habitat preferences, which are strikingly different from those of all other European populations (see Yela \& Ortíz 1990, and below). Examination of the genitalia of several individuals $(n=6)$ reinforced this concern. As shown below, the internal genital differences are sufficient to presume reproductive isolation, and thus specific status, until experimental data are available.

\subsection{Diagnosis}

Coranarta restricta Yela, sp. n. (Figs. 1a-d, 2a, $3 a-b)$

Externally, similar to the Eurasiatic species, $C$. cordigera (Europe) and C. carbonaria (Siberia

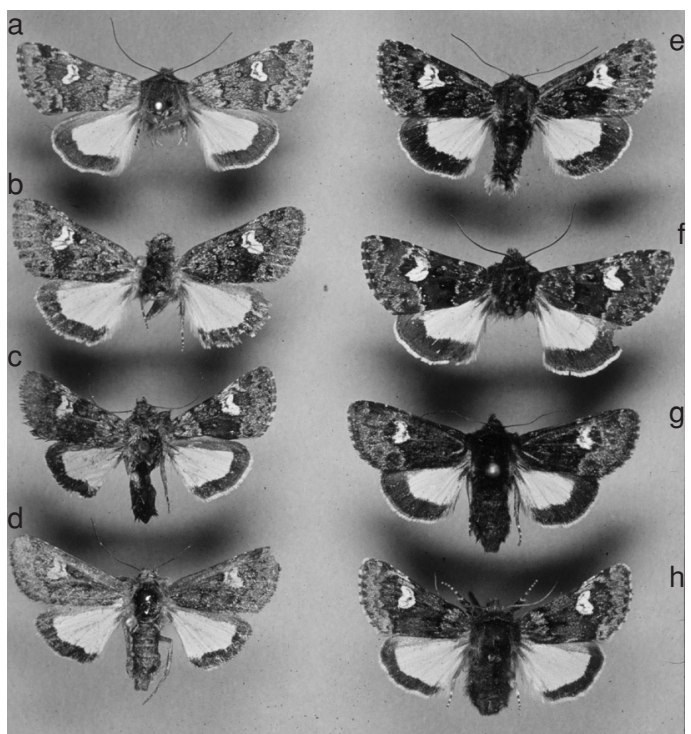

Fig. 1. Adults of Coranarta. - a. C. restricta, holotype male, Spain, Teruel, Albarracín. - b. C. restricta, paratype female, Spain, Guadalajara, Buenafuente del Sistal. - c. C. restricta, paratype female, Spain, Teruel, Bronchales. - d. C. restricta, paratype female, Spain, Teruel, Albarracín. - e. C. cordigera, male, Poland, Nowe Bagienice k. Muocgova. - f. C. cordigera, male, Germany, Kammerwald. - g. C. cordigera, dark form, female, N. Russia, Arctic Ural, Polarnyi village. - h. C. carbonaria, female, without data.

and the Far East), particularly the former, but easily distinguishable by the width of the terminal band of the hindwing, which is relatively narrower in $C$. restricta. The terminal band is rather broad in $C$. cordigera (Figs. 1e-g) and very narrow in C. carbonaria (Fig. 1h). In the male genitalia, the vesica of $C$. restricta is closest to that of $C$. cordigera, i.e. it lacks the additional subbasal diverticulum of $C$. carbonaria, but the two main diverticula are longer and the median one is directed toward the anterior part of the aedeagus, reaching its central zone. In the female genitalia, the ductus bursae is more rounded than in $C$. cordigera and C. carbonaria. Also, the bulge in the right side of the ductus bursae is smoother, the pouch in the right wall of the corpus bursae is absent or only very slightly developed and the ductus seminalis has a small pouch at its base, pointing in a more inner direction than in $C$. cordigera (similar to C. carbonaria). 


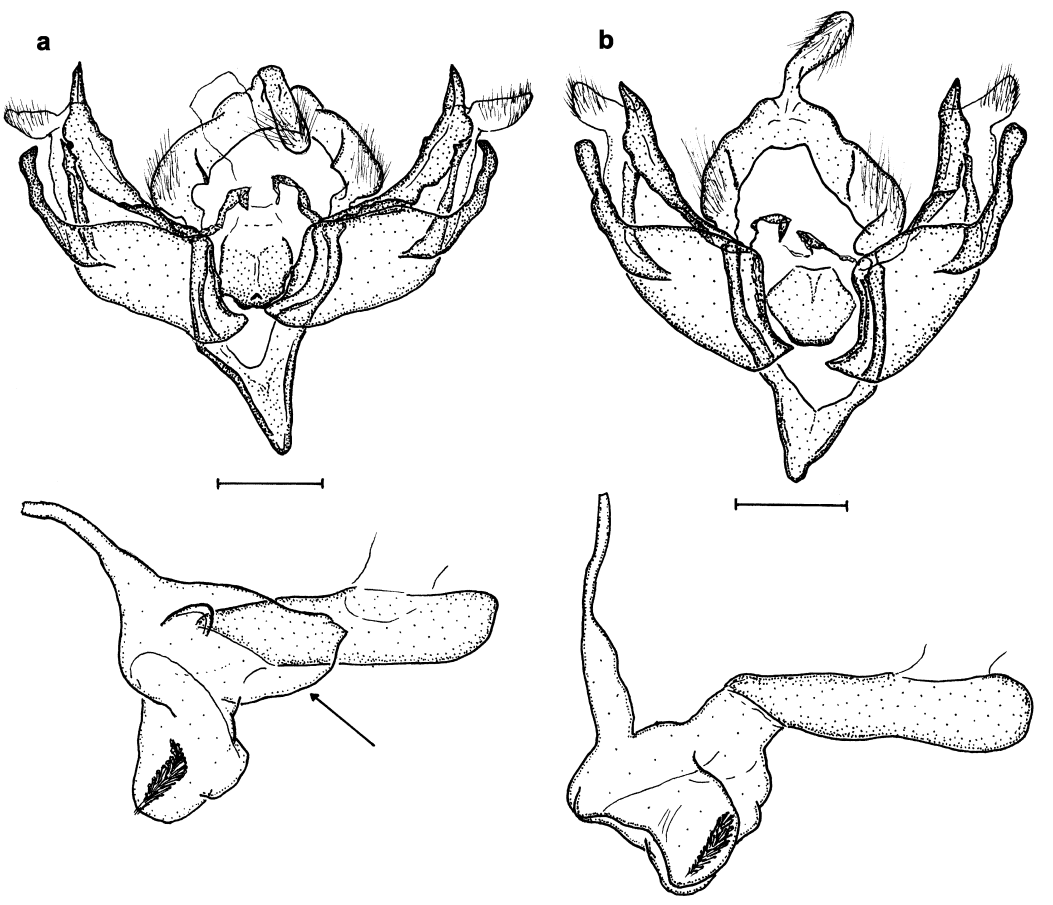

Fig. 2. Male genitalia of Coranarta. - a. C. restricta Yela, sp. n., holotype male, Spain, Teruel, Albarracín (median diverticulum indicated by an arrow) - b. C. cordigera, male, Germany, Kammerwald. Scale bars $1 \mathrm{~mm}$.

\subsection{Description}

\subsubsection{Adult}

Wingspan $21.8-26.0 \mathrm{~mm}(\overline{\mathrm{x}} \pm \sigma=24.6 \pm 1.7$; $n=5$ ). Male basal coremata absent (as in other Coranarta). Male and female antenna filiform, finely and shortly ciliate ventrally to tip; cilia more dense in male antenna. Eye reduced, elliptoid (corresponding to diurnal activity of adults). Ground colour of head, thorax and forewing above dark grey. Median field of forewing slightly darker than basal and terminal fields. Antemedian line black, straight, clearly marked in most individuals. Postmedian line less marked, relatively straight, slightly toothed on veins, not excurved around basal part of the reniform stigma (as in $C$. cordigera). Subterminal line visible as row of blackish spots in the single known male; barely visible in females. Orbicular stigma very small, dark grey, very faint. Reniform stigma large but relatively narrow, whitish, with a black longitudinal, slightly angled strip towards the centre (in C. cordigera strip is located toward inner part of reniform). Claviform stigma absent. Fringe dark grey with whitish spots at veins. Forewing under- side blackish with yellowish patch at position of reniform stigma, slightly larger than in $C$. cordigera but clearly smaller than in $C$. carbonaria (see figures 4 and 8 in Lafontaine et al. 1987). Hindwing above and below yellow in approximately basal 4/5 with grey on costa and blackish grey band on approximately the marginal $1 / 5$ of wing. On the right hindwing, the blackish band excluding fringe at vein $\mathrm{M} 1$ is $0.9-1.2 \mathrm{~mm}$ wide $(1.1 \pm 0.1 ; n=6)$, at vein Cu1a $0.7-1.1 \mathrm{~mm}$ wide $(0.9 \pm 0.1 ; n=6)$. Discal spot absent.

Male genitalia (Fig. 2a). External armature very close to that of $C$. cordigera. In the single known male, the costal extensions of valva and vinculum comparatively longer. Aedeagus also very similar to that of $C$. cordigera. Vesica consisting of relatively long and narrow subbasal diverticulum, with subapical patch of short spines and, at right, long median diverticulum directed toward anterior part of aedeagus and reaching its central zone. Median diverticulum with smooth subbasal conical elevation. Ductus ejaculatorius widened basally.

Female genitalia (Figs. 3a-b). Ovipositor short. Ductus bursae almost circular, with very smooth bulge in right side; ratio of width of duc- 

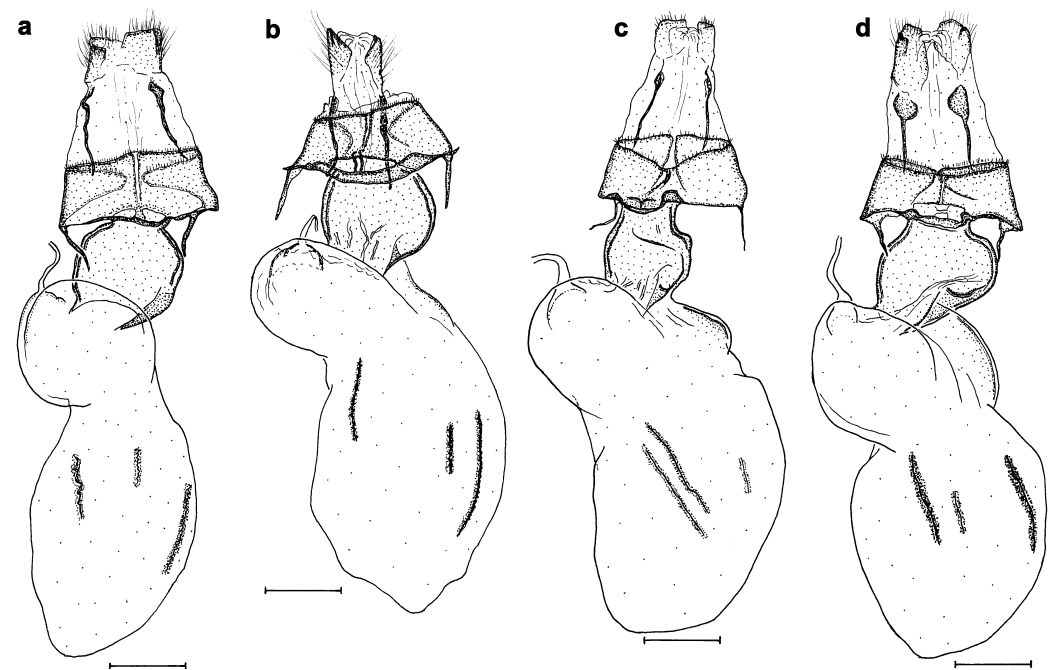

Fig. 3. Female genitalia of Coranarta, ventral view. - a. C. restricta Yela, sp. n., paratype female, Spain, Guadalajara, Buenafuente del Sistal. - b. C. restricta Yela, sp. n., paratype female, Spain, Teruel, Albarracín. - c. C. cordigera, female, Finland, Koski. - d. C. cordigera, female, without data. Genitalia shown in slightly different positions to allow better comparisons. Scale bars $1 \mathrm{~mm}$.

tus bursae (at widest segment) to that of length (at longest segment) is $1.10-1.19(1.13 \pm 0.04 ; n=5)$, in C. cordigera it is $0.90-0.99(0.94 \pm 0.04 ; n=5)$. Right wall of the corpus bursae lacking pouch (Fig. 3a) or, when present (Fig. 3b), very shallow. Corpus bursae relatively large, ellipsoidal with three longitudinal signa. Cervix bursae comparatively long and rounded. Ductus seminalis directed toward ductus bursae, with small basal pouch.

Type material. Holotype male, Spain, Teruel, Albarracín, slide 90.Y.38 (JLY), coll. T. Seebold in coll. MNCN, Madrid (type number 8987). Paratypes: 2 females, Spain, Guadalajara, Buenafuente del Sistal, 950-1000 m, 10.V.1987 and 19.IV.1993, slides 90.1591 and 90.1868 (JLY), leg. M. Ortíz in coll. JLY, Spain, Toledo; 2 females, Spain, Teruel, Albarracín, 1100-1150 m, 13.V.1929 and 21-v-1988, slides 90.Y.53 and 90.Y.49 (JLY), leg. B. H. H. Cooke (in coll. M. Fibiger, ex coll. B. H. H. Cooke; det. M. Fibiger) and leg. et coll. V. Redondo, Spain, Zaragoza; 1 female, Spain, Teruel, Bronchales, $1585 \mathrm{~m}$, V.1978, slide 90.Y.48 (JLY), leg. et coll. F. Blat, Spain, Teruel, Bronchales.

Etymology. The name restricta refers both to the restricted blackish band of the hindwings and the restricted distribution area.

\subsubsection{Early stages}

Unknown. A single last instar larva, apparently matching that of C. cordigera, was found on Arctostaphylos uva-ursi (Ericaceae) in the Tagus valley on 20.VI.1998 by a Spanish amateur colleague, some $10 \mathrm{~km}$ further SW of Buenafuente del Sistal, Guadalajara Province. The larva had dried up by the time I examined it and no morphological comparative data with the well-known larva of $C$. cordigera could be ascertained.

\subsection{Life cycle}

The moths are on the wing from mid-April to early June, with most observations and collections in May. The moths fly rapidly in bright sunshine. The males are much more active and difficult to observe and collect. Sometimes they visit flowers of Arctostaphylos and other low plants, or are found resting on the leaves of Arctostaphylos. On one single occasion (May 1987), they were observed in relatively high numbers, 10 individuals in two hours, but usually they are very scarce (all these data M. Ortíz, Guadalajara, pers. comm.). Multiple mating is common, and thus sperm 
competition is possible. The number of spermatophores found inside the bursae varies from 1 to $4(1,1,2,3,4)$. From the form and length of the ovipositor, the eggs are probably laid on the leaves of the foodplant. The only known larval foodplant (if the examined larva was actually referable to C. restricta) is Arctostaphylos uvaursi, which is also a foodplant of $C$. cordigera (e.g. Allan 1941, Mikkola \& Jalas 1977, Lorimer 1979, Koch 1984). This is the sole Ericaceae growing in all sites where $C$. restricta has been found (Table 1). Nevertheless, other Ericaceae, such as Erica australis var. aragonensis, Erica arborea and Calluna vulgaris, are present in certain sites and may also serve as larval food. I have sought larvae intensively on several occasions (late July to early September, 1997 to 2000, potential months for finding larvae of the related C. cordigera; e.g. Koch 1984), with negative results. The sampling effort includes hundreds of individuals of the putative hostplants, in every location where they grow. The larval period should last from May to late June or early July. Larvae are expected to prefer tender and young, structurally less defended leaves of the hostplant, as is usually the case with woody plant feeding noctuids. These, like $C$. restricta and the other Coranarta species, are generally univoltine (Yela \& Herrera 1993). Bud burst of Arctostaphylos uva-ursi occurs in late April and early May in Central Iberia, and relatively young leaves can be found until early-mid July. Although no pupae were found either, the pupa is expected to be subterranean and remain in the ground from June/ July until the following spring. This strategy of long aestivo-hibernation in the pupal stage is well documented both for temperate and boreal Eurasian woody plant feeding noctuids (data on single species in e.g. Forster \& Wohlfahrt 1971, Mikkola \& Jalas 1977, 1979, Lorimer 1979, 1983, Goater 1983) and for Mediterranean species (Templado 1990, Yela \& Herrera 1993; data on single species in Ronkay et al. 2001).

\subsection{Habitat associations}

A generalisation of the ecological preferences of C. restricta can be derived from Table 1 . The spe- cies has been found in 7 sites only, two of them (Buenafuente del Sistal 1 and 2) relatively close to one another. The sites are located between 950$1585 \mathrm{~m}$ altitude, in the Supra-mediterranean bioclimatic stage (Rivas-Martínez 1983, 1987), which is characterised by cold to very cold winters (as indicated by the presence of Juniperus thurifera) and warm to relatively hot and dry summers (as indicated by many xerophylic plants). There are no true bogs or peatlands in any of these sites. The ground becomes completely dry in early-mid July and remains so until mid or late August. Only in Bronchales (1585 m) and Alcalá de la Selva $(1500 \mathrm{~m})$ are some soil patches covered by bryophytes that could retain some humidity during summer, especially during rainy years. These patches are not proper peat bogs, but are to some extent their Mediterranean (wet in winter, dry in summer) counterparts. Wet patches throughout the year (true peat bogs, including Sphagnum and Drosera species), called 'tremedales' by local people, do exist in the southern Teruel province, but are scarce and no populations of $C$. restricta have yet been found in or near them. In the Bronchales and Alcalá de la Selva sites the soil is acid, favouring a slight podsolization and allowing the presence of Calluna vulgaris and Quercus pyraenaica. In the remaining sites, the soil is basic. Five sites (Albarracín -La Losilla, Buenafuente del Sistal 1 and 2, Bronchales and Alcalá de la Selva) are covered by relatively dense Mediterranean woodland with clearings (Fig. 4) and the remaining two (surroundings of Albarracín) by markedly xerophylic, open bushy-treelet formations. Common to all of them is the presence of Arctostaphylos uva-ursi as a creeping shrub. In contrast, the central and north European species, C. cordigera, is a strict tyrphobiont (e.g., Mikkola \& Spitzer 1983).

\subsection{Distribution}

C. restricta is known from a few sites in central Spain (Guadalajara and Teruel provinces). A map showing all the confirmed Iberian sites can be found in Yela \& Ortíz (1990). Fig. 5 shows the known distribution of both $C$. restricta and $C$. cordigera. 


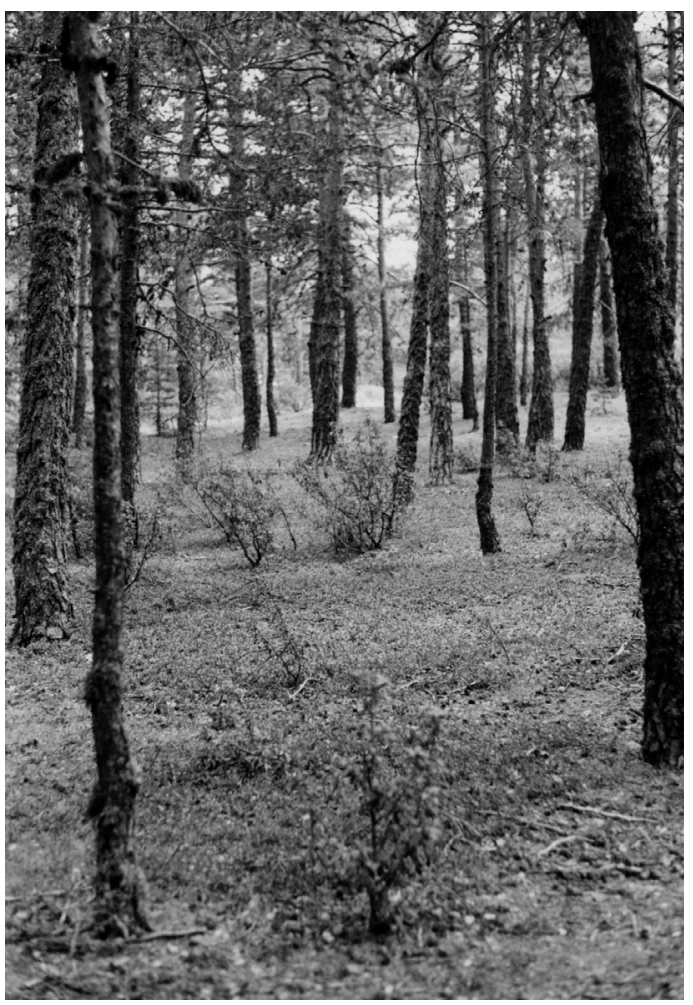

Fig. 4. Collecting site of Coranarta restricta Yela, sp. n. at Bronchales (1585 m a.s.l.): Pinus sy/vestris forest with scattered Quercus pyraenaica and Cistus laurifolius, and Arctostaphylos uva-ursi covering the ground.

\section{Discussion}

\subsection{Population and conservation biology}

No formal studies have yet been carried out to evaluate population sizes of $C$. restricta nor its spatio-temporal dynamics or functionality in the ecosystem processes. Apparently, it is a scarce species. A twenty-five and a half hour observation yielded 24 individuals at Buenafuente del Sistal (about one individual per hour; M. Ortíz pers. comm.). Due to its apparent rarity, extremely local distribution and endemic character, it is a strong candidate for inclusion in the Red Lists as an endangered, or at least vulnerable, species (categories and definitions in IUCN 2000).

Carroll et al. (1996), seeking scientific criteria for the listing process, recorded the 'inclusive

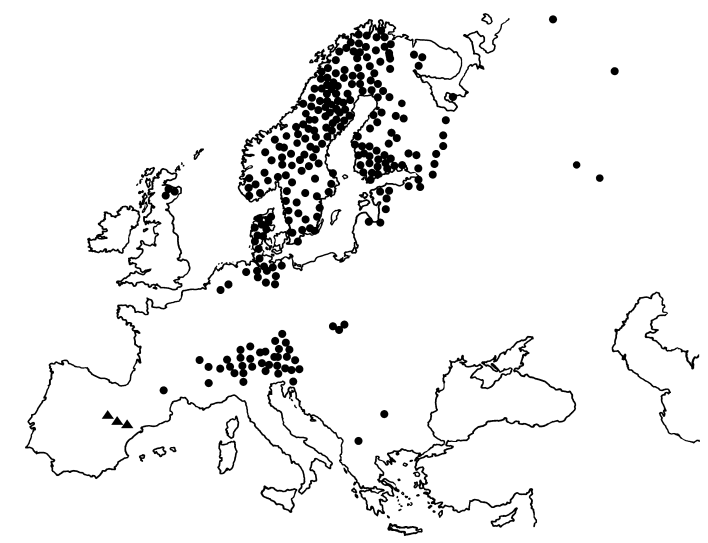

Fig. 5. Geographical distributions of Coranarta restricta Yela, sp. n. (A) and Coranarta cordigera (Thunberg, 1788) (-, according to Lafontaine et al. 1987, Nowacki \& Fibiger 1996, Beshkov 2000, Mikkola pers. comm. and unpubl. data).

benefits' that a species may produce on the whole environment. The distribution area of $C$. restricta encompasses most of the extraordinarily rich and diverse Upper Tagus Valley (data in Junta de Comunidades de Castilla-La Mancha 2001). Actions for conserving all known populations of this species and their habitats may serve as surrogates to preserve the entire region. The Upper Tagus Valley is already classed as a Natural Park (Junta de Comunidades de Castilla-La Mancha 2001). However, many floristically and faunistically unique sites located in the Upper Tagus Natural Park have already been degraded or simply ravaged by massive tourist or industrial usage during the last two decades (Yela 1992). Furthermore, a project exists to construct a golf course in the Bronchales area (a seasonally water-poor district). Thus, any sensible effort towards both the conservation of this region and its flora and fauna, and its reasonable, sustainable use would be welcome, be it based on a single-species or a multispecies approach (e.g. Simberloff 1998).

That being said, C. restricta is not a stereotypic dull and inconspicuous noctuid, but a splendid and colourful insect. Beautiful, attractive and lively animals, for example butterflies, are frequently used in conservation to attract the attention of the public opinion (so-called flagship or charismatic species; e.g. Blab \& Kudrna 1982, Collins \& Thomas 1991, New et al. 1995). Public opinion is more 
sensitive to the decline or loss of flagship species, and is thus more likely to invest in conservation programmes or to create political support for the protection of these species and their ecosystems (e.g. Meffe \& Carroll 1997, Simberloff 1998). The flagship status of $C$. restricta should be made evident and developed to conserve both the species and its habitats.

\subsection{Phylogeny and zoogeography}

The five known species of Coranarta are externally strikingly similar (see Lafontaine et al. 1987). The sclerotised parts of their genitalia are also very uniform. The most apparent differences are found in the membranous, inner parts of their genitalia. Morphological similarity suggests a relatively recent origin for the genus. In the context of Cenozoic historical events (progressive splitting and reorganisation of continents, and progressive cooling and xerophication of the Holarctic climate, e.g. de Lattin 1967, Olson 1988, Webb \& Bartlein 1992, Hewitt 1996), the distribution patterns (for details, see Lafontaine et al. 1987 and Introduction) and association with boreal/ cold-montane habitats also point towards a relatively recent origin for Coranarta.

C. restricta and C. cordigera are morphologically very closely related. The origin of $C$. restricta is plausibly related with Pleistocene contingencies (e.g. de Lattin 1959, Mikkola 1987). It is very likely a result of the well-documented north-south Pleistocene faunal migrations (Huntley \& Webb 1989, Blondel \& Aronson 1999) and concomitant isolation in the mountain ranges of the Iberian refuge, which are situated across the main migration dynamics (de Lattin 1967, Blondel \& Aronson 1999). In this context, C. restricta is a relict of Pleistocene times. Although a formal cladistic analysis is still not possible due to lack of sufficient material, the sister pair, C. restricta and $C$. cordigera, probably form the sister group of $C$. carbonaria, based on internal genital features. The separation of $C$. cordigera (or the ancestor of cordigera and restricta) from the Eastern Palaearctic C. carbonaria is plausibly related to long isolation caused by the West-Siberian wide ice-melt lake that formed between Western and Eastern Palaearctic populations in the early
Pleistocene. The Nearctic species C. luteola is also close to the group comprising $C$. restricta, $C$. cordigera and $C$. carbonaria, supporting past connections via Beringia (see Mikkola et al. 1991 for a general discussion on the Beringian refuge). The ancestral species of these four is likely to have inhabited the northern strip of the arboreal zone, with which peatlands are associated. This arboreal zone was continuous between the present Palaearctic and Nearctic during the Miocene but broke up about 6.5 million years ago (at the early Pliocene), leading to speciation between the Palaearctic and Nearctic regions (Mikkola 1987). Finally, C. macrostigma, also of the Nearctic, is probably the most phylogenetically basal species of Coranarta.

\subsection{Evolutionary mechanisms of genital dif- ferentiation and isolation}

Coranarta consists of five known species, four of them allopatric, which show remarkable differences in internal genitalia. In noctuids, internal genital differences are frequently found in congeneric, allopatric species (see Mikkola et al. 1991 for discussion on Palaearctic-Nearctic sister species, and Yela 1992 for data on European-Iberian sister species). The mechanism responsible for constant differences in the configuration of the internal genitalia between allopatric noctuid species that evolved through vicariance, that is, the driving force leading closely related noctuid species to differentiate complicated internal genitalia even in allopatry, remains in dispute (e.g. Mikkola 1993, but see Arnqvist 1998). The allopatric speciation model, as first proposed by Dobzhansky (1937, 1940), proposes that populations differentiate genetically in allopatry and that divergences in mating systems then occur at a later stage, during secondary contact. Evolution of isolation mechanisms to prevent hybridisation is called reinforcement. However, Dobzhansky's model has been challenged, because genital divergence does occur in allopatry. Thus, secondary sympatry is not necessary for the evolution of specific mating systems (Paterson 1980, 1985, Templeton 1989). Why, then, do internal genitalia differ in the absence of secondary sympatry and concomitant reinforcement? There are two 
possible explanations.

First, differences are the result of past secondary sympatry events plus reinforcement, and subsequent allopatry. Although theoretically possible, this scenario is unrealistic as a general case. Second, differences are due to steady character displacement promoted by post-mating sexual selection (e.g. sperm competition and sperm choice sensu Birkhead 2000, or e.g. sperm competition and cryptic female choice; Thornhill \& Alcock 1983, Eberhard 1985, 1996) in initially peripheral (in either an ecological or geographic sense), then later fully separated populations. There is increasing experimental evidence of sexual selection acting on genital characters in insects (Thornhill \& Alcock 1983, Shapiro \& Porter 1989, Eberhard 1985, 1990, 1993, 1996, Arnqvist 1998 and references therein; see also http://darwin.ekzool.umu.se/gaq/genital.html).

Lepidopterists studying noctuids have generally neglected or at least underestimated the role of post-mating sexual selection on genital traits. This is probably due to acceptance of the interpretation that structural matching between the internal genitalia of both sexes serves as a mechanical isolation mechanism and promotes speciation, revitalising the lock-and-key hypothesis (Lafontaine \& Mikkola 1987, Mikkola 1992, 1993). Mechanical (i.e. internal genital) isolation would play the role of a postcopulatory but prezygotic isolation mechanism. But despite the acknowledged value of the data gathered, the ultimate significance of the structural matching between the internal genitalia of both sexes in noctuids, and in ditrysian Lepidoptera in general, remains in doubt. Genital differentiation among closely related species may be merely a consequence (not necessarily of pleiotropic nature) of genetic isolation promoted by geographic separation or prezygotic isolation mechanisms (e.g. pheromonal recognition), maintained by sexual selection (e.g. Eberhard 1996, Arnqvist 1998), as described above, and not the cause of isolation and further differentiation. The general morphological similarity but divergent internal genitalia in Coranarta suggest that internal genitalia in noctuids may be subject to stronger selective pressures than other morphological structures. In fact, selective pressures tend to be stronger on reproductive traits contributing to (though not neces- sarily responsible for) reproductive isolation (e.g. Mayr 1969, O’Donald 1980). Under this scenario, post-mating sexual selection would be a plausible explanation for the differentiation of internal genitalia in allopatric noctuid sister species, an explanation that has been sought by noctuid taxonomists in recent years (e.g. Mikkola 1993). If observational and experimental data corroborate this assumption (Arnqvist 1998), structural matching in internal genitalia in noctuids would lose any significance as a mechanism of internal, mechanical isolation, and the lock-and-key hypothesis would again be shown to be unsupported.

\subsection{Internal genitalia as taxonomic tools}

Regardless of the causes and mechanisms, structural matching between the internal genitalia of both sexes has become a common $\alpha$-taxonomic tool for lepidopterists studying noctuids in recent decades (Lafontaine 1981, 1987, 1998, Lafontaine \& Poole 1991, Matthews 1991, Yela 1992, Mikkola 1992, 1993, Fibiger 1997). Even in the absence of experimental evidence with living material, this tool can still be used by morphologists. However, a fundamental question remains. Some taxa, regarded either as specific or subspecific, show very subtle differences in internal genitalia from other species or subspecies (see examples in Lafontaine 1987 and Fibiger 1997). This would appear to be evolution in progress, but it leads to the question (Ronkay et al. 2001): When are vesicas or bursas that are apparently only slightly or subtly different, sufficiently different to allow us to infer lack of sperm transfer and, consequently, lack of interbreeding and therefore specific status? This pitfall must be tackled by noctuid-taxonomists, preferably using experimental and molecular (genetic) tools. In the present case of Coranarta, such differences, together with ecological arguments, appear strong enough to imply the specific status for $C$. restricta.

Acknowledgments. Manuel Ortíz (Spain, Guadalajara) donated the specimens he collected, which first led to the consideration that there was an undescribed species, and shared his data on behaviour and sites. This work would not have been possible without his enthusiastic collaboration, and is dedicated to him. Intense and fruitful discussions on the evolution of genital differentiation and 
speciation with László Ronkay and José A. Andrés enriched this paper substantially. They, as well as Kauri Mikkola, Barry Goater and an anonymous referee, reviewed the manuscript and made numerous valuable comments. The name 'restricta' itself was brilliantly suggested by Kauri Mikkola. Additional information, data or printed material came from Adolfo Cordero, Mario Díaz, Federico Fernández, Michael Fibiger, Kauri Mikkola and László Ronkay. The following colleagues and institutions are acknowledged for the loan of material: Matti Ahola, Francisco Blat, Michael Fibiger, Isabel Izquierdo and Carolina Martín (MNCN, Madrid), Janusz Nowacki, Manuel Ortíz, Víctor M. Redondo and László and Gabor Ronkay (TM, Budapest). Thanks are also expressed to Barry Goater for the linguistic corrections.

\section{References}

Allan, P. B. M. 1949: Larval foodplants. — Garden City Press, Letchworth, Hertfordshire.

Arnqvist, G. 1998: Comparative evidence for the evolution of genitalia by sexual selection. - Nature 393: 784786.

Beck, H. 1991: Taxonomische Änderungen bei den Noctuinae, Cuculliinae und Plusiinae (Noctuidae, Lepidoptera). - Atalanta 22: 175-232.

Beck, H. 1999: Die Larven der Europäischen Noctuidae. Revision der Systematik der Noctuidae (Lepidoptera: Noctuidae). - Herbipoliana 5 (1 \& 2).

Berio, E. 1985: Lepidoptera. Noctuidae I. Generalità, Hadeninae, Cuculliinae. - Fauna d'Italia, vol. 22. Edizioni Calderini, Bologna.

Blab, J. \& Kudrna, O. 1982: Hilfsprogramm für Schmetterlinge. - Kilda-Verlag, Steinfurt.

Blondel, J. \& Aronson, J. 1999: Biology and wildlife of the Mediterranean region. - Oxford University Press, Oxford.

Byers, J. R. \& Hincks, C. F. 1978: Biosystematics of the genus Euxoa (Lepidoptera: Noctuidae). XI. Mating discrimination between three closely related species of the declarata group. - Canadian Journal of Zoology 56: 1981-1987.

Byers, J. R. \& Lafontaine, J. D. 1982: Biosystematics of the genus Euxoa (Lepidoptera: Noctuidae). XVI. Comparative biology and experimental taxonomy of four subspecies of Euxoa comosa. — Canadian Entomologist 114: 551-565.

Callahan, P. S. \& Chapin, J. B. 1960: Morphology of the reproductive systems and mating in two representative members of the family Noctuidae, Pseudaletia unipuncta and Peridroma margaritosa, with comparison to Heliothis zea. - Annals of the Entomological Society of America 53: 763-774.

Calle, J. A. 1983: Noctuidos españoles. — Boletín de Sanidad Vegetal y Plagas, suppl. 1 (1982): 1-430. [In Spanish].

Carroll, C. R., Augspurger, C., Dobson, A., Franklin, J., Orians, G., Reid, W. V., Tracy, C. R., Wilcove, D. \&
Wilson, J. 1996: Strengthening the use of science in achieving the goals of the Endangered Species Act: an assessment by the Ecological Society of America. Ecological Applications 6: 1-11.

Collins, M. R. \& Thomas, J. A. (eds.) 1991: The conservation of insects and their habitats. - Academic Press, London.

Dobzhansky, T. 1937: Genetics and the origin of species. - Columbia University Press, New York.

Dobzhansky, T. 1940: Speciation as a stage in evolutionary divergence. - American Naturalist 74: 312-321.

Eberhard, W. G. 1985: Sexual selection and animal genitalia. - Harvard University Press, Cambridge, Mass.

Eberhard, W. G. 1990: Animal genitalia and female choice. - American Scientist 78: 134-141.

Eberhard, W. G. 1993: Evaluating models of sexual selection by female choice: genitalia as a test case. - American Naturalist 142: 564-571.

Eberhard, W. G. 1996: Female control: sexual selection by cryptic female choice. - Princeton University Press, Princeton, N. J.

Fibiger, M. 1997: Noctuinae III. — In: Fibiger, M. (ed.), Noctuidae Europaeae, vol. 3. Entomological Press, Sorø.

Forster, W. \& Wohlfahrt, T. A. 1971: Eulen (Noctuidae). —Die Schmetterlinge Mitteleuropas, vol. 4. Franckh'sche Verlagshandlung Stuttgart, Stuttgart.

Goater, B. 1983: Amphipyrinae. — In: Heath, J. \& Emmett, A. M. (eds.), The moths and butterflies of Great Britain and Ireland, vol. 10. Harley Books, Colchester, Essex.

Hardwick, D. F. 1950: Preparation of slide mounts of lepidopterous genitalia. — Canadian Entomologist 82: 231235.

Hardwick, D. F. 1958: Taxonomy, life history, and habits of the elliptoid-eyed species of Schinia (Lepidoptera: Noctuidae), with notes on the Heliothidinae. - Canadian Entomologist 90 (suppl. 6): 1-116.

Hardwick, D. F. 1970: A generic revision of the North American Heliothidinae (Lepidoptera: Noctuidae). Memoirs of the Entomological Society of Canada 73: $1-59$.

Hewitt, G. M. 1996: Some genetic consequences of ice ages, and their role in divergence and speciation. - Biological Journal of the Linnean Society 58: 247-276.

Huntley, B. \& Webb, T. III. 1989: Migration: species' response to climatic variation caused by changes in the earth's orbit. - Journal of Biogeography 16: 5-19.

IUCN 2000: Red data book. - www.redlist.org

Junta de Comunidades de Castilla-La Mancha 2001: Espacios naturales. — www.jccm.es/turismo/natural/ espacios/tajo.htm

Koch, M. 1984: Schmetterlinge. — Neumann Verlag, Leipzig.

Lafontaine, J. D. 1981: Classification and phylogeny of the Euxoa detersa group (Lepidoptera: Noctuidae). Quaestiones Entomologicae 17: 1-120.

Lafontaine, J. D. 1987: Noctuoidea, Noctuidae (part). Noctuinae (part-Euxoa). — In: Dominick, R. B. et al. 
(eds.), The moths of America North of Mexico, vol. 27.2. The Wedge Entomological Research Foundation, Washington.

Lafontaine, J. D. 1998: Noctuoidea, Noctuidae (part). Noctuinae (part-Noctuini). — In: Dominick, R. B. et al. (eds.), The moths of America North of Mexico, vol. 27.3. The Wedge Entomological Research Foundation, Washington.

Lafontaine, J. D. \& Mikkola, K. 1987: Lås-och-nyckel systemen i de inre genitalierna av Noctuidae (Lepidoptera) som taxonomiska kännetecken. — Entomologiska Meddelelser, 55: 161-167. [In Swedish].

Lafontaine, J. D., Mikkola, K. \& Kononenko, V. S. 1987: Anarta cordigera (Thunberg) (Lepidoptera: Noctuidae: Hadeninae), a species complex. — Canadian Entomologist 119: 931-940.

Lafontaine, J. D. \& Poole, R. W. 1991: Noctuoidea, Noctuidae (part). Plusiinae. - In: Dominick, R. B. et al. (eds.), The moths of America North of Mexico, vol. 25.1. The Wedge Entomological Research Foundation, Washington.

Lattin, G. de 1959: Postglaziale Disjunktionen und Rassenbildung bei europäischen Lepidopteren. —Z Zoologischer Anzeiger, suppl. 22: 392-403.

Lattin, G. de 1967: Grundriss der Zoogeographie. — Gustav Fischer Verlag, Jena.

Lorimer, R. I. 1979: Hadeninae. — In: Heath, J. \& Emmett, A. M. (eds.), The Moths and Butterflies of Great Britain and Ireland, vol. 9. Curwen Books, London, pp. 196-274.

Lorimer, R. I. 1983: Cuculliinae, Acronictinae, Chloephorinae, Sarrothripinae, Pantheinae, Plusiinae, Catocalinae, Ophiderinae. - In: Heath, J. \& Emmett, A. M. (eds.), The moths and butterflies of Great Britain and Ireland, vol. 10. Harley Books, Colchester, Essex, pp. 36-147, 313-383.

Magro, R. 1994: La "técnica del silopreno" un nuevo procedimiento para el examen de vesica penis y bursa copulatrix. - SHILAP Revista de lepidopterología 22: 191-206. [In Spanish].

Matthews, M. 1991: Classification of the Heliothinae. Natural Resources Institute Bulletin 44: 1-198.

Mayr, E. 1969: Populations, species, and evolution. Belknap Press, Cambridge, Mass.

Meffe, G. K. \& Carroll, C. R. (eds.) 1997: Principles of Conservation Biology (2nd edition). - Sinauer Associates, Sunderland, Mass.

Mikkola, K. 1987: Pattern of noctuid species common between the extremities of the Palaearctic Zone: a result of glacial and postglacial movements. - Tinea 12 (suppl.): 310-315.

Mikkola, K. 1992: Evidence for lock-and-key mechanisms in the internal genitalia of the Apamea moths (Lepidoptera, Noctuidae). - Systematic Entomology 17: 145-153.

Mikkola, K. 1993: The lock-and-key mechanisms of the internal genitalia of the noctuid and geometrid moths (Lepidoptera) in relation to the speciation concepts. -
Folia Baeriana 6: 149-157.

Mikkola, K. \& Jalas, I. 1977: Suomen perhoset, vol. 1. Otava, Helsinki. [In Finnish].

Mikkola, K. \& Jalas, I. 1979: Suomen perhoset, vol. 2. Otava, Helsinki. [In Finnish].

Mikkola, K., Lafontaine, J. D. \& Kononenko, V. S. 1991: Zoogeography of Holarctic species of Noctuidae (Lepidoptera): importance of the Beringian refuge. Entomologica Fennica 2: 157-173.

Mikkola, K. \& Spitzer, K. 1993: Lepidoptera associated with peatlands in central and northern Europe: a synthesis. - Nota lepidopterologica 6: 216-229.

New, T. R., Pyle, R. M., Thomas, J. A., Thomas, C. D. \& Hammond, P. C. 1995: Butterfly conservation management. - Annual Review of Entomology 40: 57-83.

O'Donald, P. 1980: Genetic models of sexual selection. Cambridge University Press, Cambridge.

Olson, S. L. 1988: Aspects of global avifauna dynamics during the Cenozoic. - Acta XIX Congressus Internationalis Ornithologici, vol. 2. University of Ottawa Press, Ottawa, pp. 2023-2029.

Paterson, H. E. H. 1980: A comment on 'mate recognition systems'. - Evolution 34: 330-331.

Paterson, H. E. H. 1985: The recognition concept of species. - In: Vrba, E. S. (ed.), Species and speciation. Transvaal Museum Monographs 4, Pretoria, pp. 2134.

Rivas-Martínez, S. 1983: Pisos bioclimáticos de España. - Lazaroa, 5: 33-43. [In Spanish].

Rivas-Martínez, S. (ed.) 1987: Memoria del mapa de series de vegetación de España. - I.C.O.N.A., Madrid. [In Spanish].

Ronkay, L., Yela, J. L \& Hreblay, M. 2001: Hadeninae II. — In: Fibiger, M. (ed.), Noctuidae Europaeae, vol. 5. Entomological Press, Sorø.

Shapiro, A. M. \& Porter, A. H. 1989: The lock-and-key hypothesis: evolutionary and biosystematic interpretation of insect genitalia. - Annual Review of Entomology 34: 231-245.

Simberloff, D. 1998: Flagships, umbrellas, and keystones: is single-species management passé in the landscape era? - Biological Conservation 83: 247-257.

StatSoft 1999: STATISTICA for Windows, release 5.5. StatSoft, Inc. Tulsa, Ok.

Thornhill, R. \& Alcock, J. 1983: The evolution of insect mating systems. - Harvard University Press, Cambridge, Mass.

Templado, J. 1990: Datos fenológicos sobre lepidópteros defoliadores de la encina (Quercus ilex L.). - SHILAP Revista de lepidopterología 18: 325-334. [In Spanish].

Templeton, A. R. 1989: The meaning of species and speciation: a genetic perspective. - In: Otte, D. \& Endler, J. A. (eds.), Speciation and its consequences. Sinauer Associates, Sunderland, Mass, pp. 3-27.

Webb, T. III \& Bartlein, P. J. 1992: Global changes during the last 3 million years: climatic controls and biotic responses. - Annual Review of Ecology and Systematics 23: 141-173. 
Yela, J. L. 1992: Los Noctuidos (Lepidoptera) de la Alcarria (España Central) y su relación con las principales formaciones vegetales de porte arbóreo. - Ministerio de Agricultura, Pesca y Alimentación, Madrid. [In Spanish].

Yela, J. L. 1998: Noctuidos del área iberobalear: adiciones y correcciones a la lista sistemática, con consideraciones micro y macroevolutivas y una propuesta filogenética global (Insecta: Lepidoptera: Noctuidae). — Zapateri 7 (1997): 91-190. [In Spanish].
Yela, J. L. \& Herrera, C. M. 1993: Seasonality and life cycles of woody plant-feeding noctuid moths (Lepidoptera: Noctuidae) in Mediterranean habitats. - Ecological Entomology 18: 259-269.

Yela, J. L. \& Ortíz, M. 1990: Acerca de las preferencias ecológicas y de la distribución de Anarta cordigera (Thunberg, 1788) en la Península Ibérica (Lepidoptera, Noctuidae, Hadeninae). - Ecología 4: 339-342. [In Spanish]. 